\title{
Medication Storage at Home among People in Al-Qassim Region, Saudi Arabia
}

\author{
Afaf Badr Alenazi ${ }^{1{ }^{1 *},}$ Mansour Saleh Alsharidah², Amal Hassan Al-Najjar ${ }^{3 *}$, Suliman Abdulaziz \\ Alghazy $^{4}$, Abdul-Aziz Abdullah Alqadi ${ }^{5}$, Amir Marzouk ${ }^{6}$ \\ ${ }^{1}$ College of Pharmacy, Qassim University, \\ ${ }^{2}$ Assistant Professor. Dean College of Pharmacy, Qassim University, \\ ${ }^{3}$ Drug Information Supervisor, SFHP-Riyadh, \\ ${ }^{4}$ College of Pharmacy, Qassim University3, \\ ${ }^{5}$ Acute Clinical Care Supervisor, SFHP-Riyadh, \\ ${ }^{6}$ The research center College of Medicine, King Saud University KSA.
}

\begin{abstract}
Objective: Storing medications at home is a global practice. By storing medications in an appropriate and safe environment, we can prevent accidental poisoning. Information is scarce regarding the storage of different types of medications at homes in Al-Qassim region, Kingdom of Saudi Arabia. Therefore, in this study, we aimed to explore the types of medications stored at homes among people residing in Al-Qassim region. Methodology: This is a descriptive, cross-sectional survey conducted through the random distribution of a pre-validated structured questionnaire among the public and private sector employees and people from all walks of life above the age of 18 years in Al-Qassim region. The survey was designed electronically through Survey Monkey system and was distributed through social media. Results: A total of 708 subjects responded to the survey. Most of the responders were females (485 (68.10\%)). About half of the responders were in the age group of 18-29 years (393 (58.31\%)) with a significantly dominant female population as compared to males $(p<0.05)$. The most frequently stored medications were related to headache $(462(65.25 \%))$ and pain $(445(62.85 \%))$. Most of the responders stored their medications in the refrigerator $(467(65.96 \%))$ or in their bedroom (324 (45.76\%)). A total of 633 medications were found to be stored at homes during this survey. The top 20 most frequently stored medications were paracetamol $(266(42.02 \%))$ and ibuprofen $(42(6.64 \%))$. Conclusion: The results of this study show an alarming situation about the methods of storing medication and types of medicines stored among the residents of Al-Qassim region. More and more campaigns and awareness programs should be conducted through different types of social media to educate the people regarding the appropriate methods of storing medications at home. Such awareness programs should stress more regarding safe methods of storage and spread awareness regarding how to identify the appropriate method of disposal to prevent harmful impact on the environment.
\end{abstract}

Key words: Pattern, Al-Qassim, Medication Storage, Home, Saudi Arabia.
Received: 8-10-2018;

Accepted: 29-11-2018

*Correspondence to:

Dr. Amal Hassan Al-Najjar Drug Information Supervisor, Security Forces Hospital, Riyadh, Saudi Arabia, SAUDI ARABIA.

Phone no: +966504130480 Email: aalnajjar66@gmail.com DOI: 10.5530/ijpcs.2019.8.10

Copyright: (c) the author(s),publisher and licensee International Journal of Pharmacology and Clinical Sciences. This is an open-access article distributed under the terms of the Creative Commons Attribution Non-Commercial License, which permits unrestricted non-commercial use, distribution, and reproduction in any medium, provided the original work is properly cited.

This is an open access article distributed under the terms of the Creative Commons AttributionNonCommercial-ShareAlike 4.0 License

Access this article online

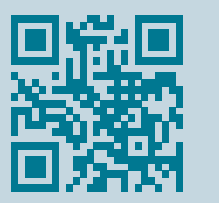

www.ijpcs.net 


\section{INTRODUCTION}

The rational use of medicine justifies the appropriateness in its use according to WHO (2012). ${ }^{[1]}$ It entails giving patients the right medication for an ailment or need in addition to carrying it in the right proportion and within the timeframe and at the lowest possible cost without compromising on efficacy. ${ }^{[2]}$ In general, medicines could either be used rationally or irrationally. Irrational use of medication is very dangerous to the patient. Even though the wrong use of medication is a global issue, we can see it more among the developing nations due to less effective monitoring or due to the complete absence of tracking of medicines that are being used irrationally.

${ }^{[3]}$ Eventually, this leads to various issues such as greater health risks, resistance toward the medication in question, treatment not working, wastage of resources invested in purchasing the drugs and increased rate of morbidity and mortality. ${ }^{[4]}$ To tackle this issue, there is an urgent need to involve people in understanding the rational use of medicine and to work together in phasing out the wrong use of medication. ${ }^{[3]}$

Medicines found in households are those that are commonly purchased through prescriptions from healthcare institutions and dispensaries or those that are purchased without prescriptions from retail pharmacies, friends and other resources. Occasionally, these medicines will be consumed for their illness soon after their purchase or will be stored in their home for future use. ${ }^{[5]}$ On other occasions, they use it for self-medication purposes or for emergency purposes.

Self-medication is a worldwide phenomenon and is practiced globally to address their health problems without consulting a medical professional. ${ }^{[6]}$ Most of the time, frequent access to drugs by the elderly who suffer from multiple diseases leads to the piling of leftover medications that will not be used any more at home. ${ }^{[7]}$ According to Wasserfallen et al. elderly patients and households with more people are more likely to store unused drugs. ${ }^{[7-9]}$ Moreover, sharing medications might increase their number at home, thus making it difficult to control their use by unintentional users such as children who could accidentally consume the mediations that they are not supposed to. ${ }^{[10]}$

On an average, Abou-Auda has shown that each household in Saudi Arabia stores at least eight drugs at home and about $30 \%$ of the population at least stores up to 10.6 medications. Abahussain, Ball and Matowe have shown that $98 \%$ of the families in Sudan stored at least one drug at home. About $40 \%$ of the families surveyed in Uganda stored medications at home. ${ }^{[12]}$ Nearly $20 \%$ of the Ethiopian families studied hoarded drugs and $17 \%$ practiced drug sharing. ${ }^{[13]}$

The accumulated home-stored drugs eventually pose a problem when there is a need for disposal, which is a great concern to the local and national health and environmental authorities because most of the drugs are disposed inappropriately through flushing down the toilet or sink which drains into the water supplies. ${ }^{[12]}$ This happens because people have little or no information regarding the storage and disposal of medications. ${ }^{[14]}$ Therefore, in this study, we aimed to assess the type and number of medicines stored at home in Al-Qassim region, Saudi Arabia. We also aimed to assess if the storage method had any impact on poisoning cases occurring in the area. In addition, we gathered information regarding medication storage behaviors, generated data that clarify the pattern of home storage of medications and explored the reasons behind home storage patterns of medicines.

\section{MATERIALS AND METHODS}

This is a 1-month cross-sectional survey conducted through the random distribution of the structured questionnaire in Al-Qassim region in 2017 to students, public and private sector employees and to people from all walks of life above the age of 18 years. The questionnaire was designed in English and the Arabic version was validated by the research team. The survey consisted two sections: the first section collected information regarding sociodemographic characteristics of the respondents such as gender, age, educational level, number of members living in their home, presence of elderly members at home and if there is any family member working in the healthcare sector. The second section collected information regarding medicines stored at home; in this section, the participants were asked about the medication available at home, such as number of drugs stored, their dosage forms, source of drugs and for what conditions those medicines were used. Furthermore, they were asked about reasons for keeping these medications at home and where they were stored. The survey was designed electronically through Survey Monkey system and distributed through social media. In addition, 100 copies of the questionnaire were printed and distributed across various locations of Al-Qassim region. The data were analyzed using Survey Monkey system and SPSS version 22 . 


\section{RESULTS}

A total of 708 subjects responded to this survey. Most of them were females (485 (68.10\%)). About half of the responders were in the age group of 18-29 years $(393(58.31 \%))$ with a significantly dominant female population over male $(p<0.05)$, whereas $30 \%$ (206) of the responders were in the age group of 30-39 years without any differences in the gender. With respect to the educational status, 592 (83.62\%) responders had completed their higher education with a significantly dominant female population $(p<0.05)$. Most of the families comprised 5-7 members (299
(42.23\%)) followed by families comprising more than 8-10 members $(183(26 \%))$ and families comprising $2-4$ members $(163(23 \%))$ without any significant differences in their educational status $(p>0.05)$. A total of $493(69.63 \%)$ responders had at least one elderly person in their home regardless of any significant differences in age and educational status $(p>0.05)$. However, $322(45.48 \%)$ responders had at least one family member who was working in the healthcare sector with females being significantly more than that of males and without any significant differences in educational status $(p>0.05)$ (Table 1$)$. Majority of the responders had at least five medications

\begin{tabular}{|c|c|c|c|}
\hline & Response Count & Response Percent & Comments \\
\hline \multicolumn{4}{|l|}{ Sex } \\
\hline Female & 485 & $68.50 \%$ & \\
\hline Male & 223 & $31.50 \%$ & \\
\hline Answered questions & 708 & & \\
\hline Skipped questions & 0 & & \\
\hline \multicolumn{4}{|l|}{ Age } \\
\hline $18-29$ & 412 & $58.19 \%$ & $\mathrm{~F}$ more than $\mathrm{M} P<0.05$ \\
\hline $30-39$ & 216 & $30.51 \%$ & \\
\hline $40-49$ & 60 & $8.47 \%$ & $\mathrm{M}$ more than $\mathrm{F} P<0.05$ \\
\hline $50-59$ & 15 & $2.12 \%$ & \\
\hline $60+$ & 5 & $0.71 \%$ & M more than $\mathrm{F} P<0.05$ \\
\hline Answered questions & 708 & & \\
\hline Skipped questions & 0 & & \\
\hline \multicolumn{4}{|l|}{ Educational status } \\
\hline Illiterate & 0 & $0.00 \%$ & \\
\hline Primary/intermediate & 8 & $1.13 \%$ & \\
\hline Secondary & 108 & $15.25 \%$ & M more than $\mathrm{F} P<0.05$ \\
\hline University / more & 592 & $83.62 \%$ & $\mathrm{~F}$ more than $\mathrm{M} P<0.05$ \\
\hline Answered questions & 708 & & \\
\hline Skipped questions & 0 & & \\
\hline \multicolumn{4}{|c|}{ How many family members in your house? } \\
\hline $2-4$ & 163 & $23.02 \%$ & \multirow{6}{*}{$P>0.05$ in the Educational status factor } \\
\hline $5-7$ & 299 & $42.23 \%$ & \\
\hline $8-10$ & 183 & $25.85 \%$ & \\
\hline More than 10 & 63 & $8.90 \%$ & \\
\hline Answered questions & 708 & $23.02 \%$ & \\
\hline Skipped questions & 0 & & \\
\hline \multicolumn{4}{|c|}{ Do you have any elderly in your family? } \\
\hline Yes & 493 & $69.63 \%$ & \multirow{4}{*}{$\begin{array}{l}P>0.05 \text { in the gender factor } \\
P>0.05 \text { in the Educational status factor }\end{array}$} \\
\hline No & 215 & $30.37 \%$ & \\
\hline Answered questions & 708 & & \\
\hline Skipped questions & 0 & & \\
\hline \multicolumn{4}{|c|}{ Is there any member in your family working in Health sector? } \\
\hline Yes & 322 & $45.48 \%$ & $\mathrm{~F}$ more than $\mathrm{M} P<0.05$ \\
\hline No & 386 & $54.52 \%$ & M more than $\mathrm{F} P<0.05$ \\
\hline Answered questions & 708 & & \multirow[t]{2}{*}{$P>0.05$ in the Educational status factor } \\
\hline Skipped questions & 0 & & \\
\hline
\end{tabular}


(445 (62.85\%)) stored at home; female responders stored 2-5 medications more $(p<0.05)$, whereas male responders did not store more than four medications. The highest number (4-5 or more) of medicines stored were by people in the age group of $18-29$ years $(p<0.05)$. Responders with a higher level of educational status (university level) tended to store highest number of medications $(p<0.05)$ (Tables $2-5)$. The most frequently stored medications were related to headache $(462(65.25 \%))$ and pain $(445(62.85 \%))$ followed by medications related to fever $(427(60.31 \%))$ and diabetes mellitus without any significant differences related to gender or educational status $(p>0.05)$. The most frequently stored drug form was tablet (664 (93.79\%)) and capsule (389 (54.94\%)) followed by ointment/cream (357 (50.42\%)) and oral liquid (217 (30.65\%)) without any significant differences related to gender or educational status $(p>0.05)$
(Table 3). Most of the responders stored their medications in the refrigerator $(467(65.96 \%))$ or in the bedroom (324 (45.76\%)) followed by storing them on table/shelf $(183(25.85 \%))$ and in private cabinet (153 $(21.61 \%))$ without any significant differences related to gender or educational status $(p>0.05)$. Most of the responders stored the medications at appropriate temperature (541 (76.41\%)) without any significant differences related to gender or educational status $(p>0.05)$, except for responders with university level of education who were keener to store appropriately than that of secondary school and degree holders. Majority of the responders stored the medications in original container (553 (78.11\%)) without any significant differences related to gender or educational status $(p>0.05)$. Most of the responders did not store multiple medications in the same container without any significant differences related to gender or educational

\begin{tabular}{|c|c|c|c|}
\hline & Response Count & Response Percent & Comments \\
\hline \multicolumn{3}{|c|}{ What is the number of medications stored at your home? } & \\
\hline 1 & 27 & $3.81 \%$ & \multirow{7}{*}{$\begin{array}{l}P>0.05 \text { in the Educational status factor except } \\
\text { for participant who are at university level found to } \\
\text { store more than four medications (Five or more) }\end{array}$} \\
\hline 2 & 57 & $8.05 \%$ & \\
\hline 3 & 100 & $14.12 \%$ & \\
\hline 4 & 79 & $11.16 \%$ & \\
\hline Five or more & 445 & $62.85 \%$ & \\
\hline Answered questions & 708 & & \\
\hline Skipped questions & 0 & & \\
\hline \multicolumn{3}{|c|}{ Which conditions/ illness you got these medications? } & \\
\hline Headache & 462 & $65.25 \%$ & \multirow{13}{*}{$\begin{array}{l}P>0.05 \text { in the gender factor } \\
P>0.05 \text { in the Educational status factor }\end{array}$} \\
\hline Pain & 445 & $62.85 \%$ & \\
\hline Fever & 427 & $60.31 \%$ & \\
\hline Diabetes mellitus & 263 & $37.15 \%$ & \\
\hline Hypertension & 218 & $30.79 \%$ & \\
\hline Unspecified & 181 & $25.56 \%$ & \\
\hline Eye problem & 180 & $25.42 \%$ & \\
\hline Asthma & 136 & $19.21 \%$ & \\
\hline Peptic ulcer disease & 107 & $15.11 \%$ & \\
\hline Rheumatoid arthritis & 102 & $14.41 \%$ & \\
\hline Psychiatric & 51 & $7.20 \%$ & \\
\hline Answered questions & 708 & & \\
\hline Skipped questions & 0 & & \\
\hline \multicolumn{3}{|c|}{ What type of dosage forms do you have? } & \\
\hline Tablet & 664 & $93.79 \%$ & \multirow{8}{*}{$\begin{array}{l}P>0.05 \text { in the gender factor } \\
P>0.05 \text { in the Educational status factor }\end{array}$} \\
\hline Capsule & 389 & $54.94 \%$ & \\
\hline Ointment/ cream & 357 & $50.42 \%$ & \\
\hline Oral liquid & 217 & $30.65 \%$ & \\
\hline Drops & 211 & $29.80 \%$ & \\
\hline Injection & 83 & $11.72 \%$ & \\
\hline Answered questions & 708 & & \\
\hline Skipped questions & 0 & & \\
\hline
\end{tabular}




\begin{tabular}{|c|c|c|c|c|}
\hline Number of medications & Male & Female & Total & P value \\
\hline \multirow{2}{*}{ One Medications (A) } & 7 & 20 & 27 & \\
\hline & $25.93 \%$ & $74.07 \%$ & $3.81 \%$ & \\
\hline \multirow{3}{*}{ Two Medications (B) } & $26.32 \%$ & $73.68 \%$ & $8.05 \%$ & \\
\hline & 15 & 42 & 57 & \\
\hline & $\mathrm{D}$ & $\mathrm{D}$ & & $P<0.05$ \\
\hline \multirow{3}{*}{ Three Medications (C) } & $31.00 \%$ & $69.00 \%$ & $14.12 \%$ & \\
\hline & 31 & 69 & 100 & \\
\hline & $\mathrm{D}$ & $\mathrm{D}$ & & $P<0.05$ \\
\hline \multirow{3}{*}{ Four Medications (D) } & $45.57 \%$ & $54.43 \%$ & $11.16 \%$ & \\
\hline & 36 & 43 & 79 & \\
\hline & BCE & $\mathrm{BCE}$ & & $P<0.05$ \\
\hline \multirow{3}{*}{ Five or more Medications $(E)$} & $30.11 \%$ & $69.89 \%$ & $62.85 \%$ & \\
\hline & 134 & 311 & 445 & \\
\hline & $\mathrm{D}$ & $\mathrm{D}$ & & $P<0.05$ \\
\hline Total Respondents & 223 & 485 & 708 & \\
\hline
\end{tabular}

\begin{tabular}{|c|c|c|c|c|c|c|c|}
\hline Number of medications & $18-29$ & $30-39$ & $40-49$ & $50-59$ & $60+$ & TOTAL & $P$ value \\
\hline \multirow{2}{*}{ One Medications (A) } & $51.85 \%$ & $44.44 \%$ & $3.70 \%$ & $0.00 \%$ & $0.00 \%$ & $3.81 \%$ & \\
\hline & 14 & 12 & 1 & 0 & 0 & 27 & \\
\hline \multirow{2}{*}{ Two Medications (B) } & $50.88 \%$ & $36.84 \%$ & $10.53 \%$ & $1.75 \%$ & $0.00 \%$ & $8.05 \%$ & \\
\hline & 29 & 21 & 6 & 1 & 0 & 57 & \\
\hline \multirow{2}{*}{ Three Medications (C) } & $54.00 \%$ & $34.00 \%$ & $8.00 \%$ & $3.00 \%$ & $1.00 \%$ & $14.12 \%$ & \\
\hline & 54 & 34 & 8 & 3 & 1 & 100 & \\
\hline \multirow{3}{*}{ Four Medications (D) } & $40.51 \%$ & $36.71 \%$ & $15.19 \%$ & $5.06 \%$ & $2.53 \%$ & $11.16 \%$ & \\
\hline & 32 & 29 & 12 & 4 & 2 & 79 & \\
\hline & $E$ & & $\mathrm{E}$ & $\mathrm{E}$ & $E$ & & $\mathrm{P}<0.05$ \\
\hline \multirow{3}{*}{ Five or more Medications ( $E$ ) } & $63.60 \%$ & $26.97 \%$ & $7.42 \%$ & $1.57 \%$ & $0.45 \%$ & $62.85 \%$ & \\
\hline & 283 & 120 & 33 & 7 & 2 & 445 & \\
\hline & $\mathrm{D}$ & & $\mathrm{D}$ & $\mathrm{D}$ & $\mathrm{D}$ & & $\mathrm{P}<0.05$ \\
\hline Total Respondents & 412 & 216 & 60 & 15 & 5 & 708 & \\
\hline
\end{tabular}

\begin{tabular}{|c|c|c|c|c|c|c|}
\hline Number of medications & Illiterate & $\begin{array}{l}\text { Primary/ } \\
\text { Intermediate }\end{array}$ & Secondary & $\begin{array}{l}\text { University or } \\
\text { more }\end{array}$ & Total & $P$ value \\
\hline \multirow{2}{*}{ One Medications (A) } & & & & & & \\
\hline & $0.00 \%$ & $0.00 \%$ & $14.81 \%$ & $85.19 \%$ & $3.81 \%$ & \\
\hline \multirow{2}{*}{ Two Medications (B) } & 0 & 0 & 4 & 23 & 27 & \\
\hline & $0.00 \%$ & $0.00 \%$ & $22.81 \%$ & $77.19 \%$ & $8.05 \%$ & \\
\hline \multirow{2}{*}{ Three Medications (C) } & 0 & 0 & 13 & 44 & 57 & \\
\hline & $0.00 \%$ & $2.00 \%$ & $13.00 \%$ & $85.00 \%$ & $14.12 \%$ & \\
\hline \multirow{3}{*}{ Four Medications (D) } & $0.00 \%$ & $2.53 \%$ & $21.52 \%$ & $75.95 \%$ & $11.16 \%$ & \\
\hline & 0 & 2 & 17 & 60 & 79 & \\
\hline & & & & $\mathrm{E}$ & & $P<0.05$ \\
\hline \multirow{3}{*}{ Five or more Medications $(E)$} & $0.00 \%$ & $0.90 \%$ & $13.71 \%$ & $85.39 \%$ & $62.85 \%$ & \\
\hline & 0 & 4 & 61 & 380 & 445 & \\
\hline & & & & $\mathrm{D}$ & & $P<0.05$ \\
\hline Total Respondents & 0 & 8 & 108 & 592 & 708 & \\
\hline
\end{tabular}




\begin{tabular}{|c|c|c|c|}
\hline & Response Count & $\begin{array}{l}\text { Response } \\
\text { Percent }\end{array}$ & Comments \\
\hline \multicolumn{3}{|c|}{ Where do you store these medications? } & \\
\hline Refrigerator & 467 & $65.96 \%$ & \multirow{9}{*}{$\begin{array}{l}P>0.05 \text { in the gender factor for all except hand bag } F \text { more than male } \\
P>0.05 \text { in the Educational status factor }\end{array}$} \\
\hline Bedroom & 324 & $45.76 \%$ & \\
\hline Table/ Shelf & 183 & $25.85 \%$ & \\
\hline Private Cabinet & 153 & $21.61 \%$ & \\
\hline Hand bag & 110 & $15.54 \%$ & \\
\hline Others & 34 & $4.80 \%$ & \\
\hline Bathroom & 6 & $0.85 \%$ & \\
\hline Answered questions & 708 & & \\
\hline Skipped questions & 0 & & \\
\hline \multicolumn{4}{|c|}{ Do you store the medication at the appropriate room temperature (up to $30 \mathrm{C}$ )? } \\
\hline Yes & 541 & $76.41 \%$ & \multirow{4}{*}{$\begin{array}{l}P>0.05 \text { in the gender factor } \\
P>0.05 \text { in the Educational status factor except at university level more keen to store } \\
\text { medication at room temp than secondary level }\end{array}$} \\
\hline No & 167 & $23.59 \%$ & \\
\hline Answered questions & 708 & & \\
\hline Skipped questions & 0 & & \\
\hline \multicolumn{4}{|c|}{ Do you keep the medication in its original container with its leaflet? } \\
\hline Yes & 553 & $78.11 \%$ & \multirow{4}{*}{$\begin{array}{l}P>0.05 \text { in the gender factor } \\
P>0.05 \text { in the Educational status factor }\end{array}$} \\
\hline No & 155 & $21.89 \%$ & \\
\hline Answered questions & 708 & & \\
\hline Skipped questions & 0 & & \\
\hline \multicolumn{3}{|c|}{ Do you store multiple medications in the same vial? } & \\
\hline Yes & 89 & $13.09 \%$ & \multirow{5}{*}{$\begin{array}{l}P>0.05 \text { in the gender factor } \\
P>0.05 \text { in the Educational status factor except at secondary level more mostly to store } \\
\text { multiple medication than university level }\end{array}$} \\
\hline Mostly & 89 & $13.09 \%$ & \\
\hline No & 502 & $73.82 \%$ & \\
\hline Answered questions & 680 & & \\
\hline Skipped questions & 28 & & \\
\hline
\end{tabular}

\begin{tabular}{|c|c|c|c|}
\hline No & Medication & Frequency & Percentages \\
\hline 1 & Paracetamol & 266 & $42.02 \%$ \\
\hline 2 & Ibuprofen & 42 & $6.64 \%$ \\
\hline 3 & Diclofenac & 42 & $6.64 \%$ \\
\hline 4 & Naproxen & 23 & $3.63 \%$ \\
\hline 5 & Multivitamins & 21 & $3.32 \%$ \\
\hline 6 & Metformin & 18 & $2.84 \%$ \\
\hline 7 & Aspirin & 16 & $2.53 \%$ \\
\hline 8 & Amoxicillin & 14 & $2.21 \%$ \\
\hline 9 & Levothyroxine & 14 & $2.21 \%$ \\
\hline 10 & Chlorpheniramine & 12 & $1.90 \%$ \\
\hline 11 & Ranitidine & 11 & $1.74 \%$ \\
\hline 12 & Salbutamol & 10 & $1.58 \%$ \\
\hline 13 & Loratadine & 8 & $1.26 \%$ \\
\hline 14 & Amlodipine & 7 & $1.11 \%$ \\
\hline 15 & Vitamin C & 7 & $1.11 \%$ \\
\hline 16 & Vitamin D & 7 & $1.11 \%$ \\
\hline 17 & Iron & 7 & $1.11 \%$ \\
\hline 18 & B Sitosterol & 5 & $0.79 \%$ \\
\hline 19 & Pseudoephedrine & 4 & $0.63 \%$ \\
\hline 20 & Diphenhydramine & 4 & $0.63 \%$ \\
\hline
\end{tabular}

status $(p>0.05)$. However, responders of secondary school and degree holders stored more items than responders at university level of education (Table 6). A total of 633 medications were stored in homes. The top 20 most frequently stored medications were paracetamol (266 (42.02\%)) and ibuprofen (42 (6.64\%)) followed by diclofenac $(42(6.64 \%))$ and naproxen (23 (3.63\%)) (Table 7).

\section{DISCUSSION}

In this study, we address the issue of storing medications at home by the people residing in Al-Qassim region, especially on the significant lack of information regarding storing and disposing medications. We investigated 708 participants related to their method of storing medications and types of medicines stored from different perspectives such as age, gender, educational status and presence of different family members. Our study showed that most of the responders were young females and highly educated. This might be because more Saudi females accepted to respond to the survey in 
order to gain knowledge and improve their medications use. Most of the female responders stored at least two medications in their house, whereas male responders did not store more than four medications, which shows that females have the tendency to store medications more than males. Jassim found that on an average 14.26 medications were stored in the households in Basrah, Iraq (range: 1-72 per household). ${ }^{[14]}$ The results also showed that most families (70\%) stored between 1-20 medications. However, it was noted that more medications were stored by respondents with higher level of education without an apparent reason. Similar results were reported by McNulty where she found that the most educated respondents were twice as likely as those least educated to have leftover antimicrobial drugs (5.4\% with a university degree vs. $2.4 \%$ with no formal degree). ${ }^{[15]}$ The most compelling indications to store medications were headache, pain and fever, which might be the most common ailments noted among responders.

The number of responders who stored medication at home is roughly more than half of the population of Al-Qassim region, which agrees with the results of McNulty's study; $44 \%$ of the study population in her study stored medications for future use. ${ }^{[15]}$ However, all respondents had the habit of storing medications in refrigerators regardless of their storing conditions and regardless of their age or their educational status. Only 516 respondents stored medications at appropriate temperature and the remaining respondents did not pay attention to the storage conditions. Storing medications in inappropriate conditions can negatively affect the health of the individual. As a general rule, storing medications at home for chronic illnesses is justified as the patients receive their supply for 3-6 months. However, the crucial point is the storage of these medications in proper conditions. This is especially true for KSA as it is a region with high temperature for most of the year. Around two-third of the respondents were aware of temperature constraints and the need to store medication under $30^{\circ} \mathrm{C}$.

This study shows that most of the medications stored were in the form of either tablets, capsules, ointments, or oral liquids, whereas injection were least stored medications. In the case of injections, they were rarely prescribed as an outpatient medication and therefore the families of patients needing an injection did not store unless it was needed. A previous study has also shown similar results. ${ }^{[9]}$
Our results show that with advanced age, the tendency of storing medications at home was less; which could be due to the increased awareness of their age and their desire to eliminate any excess medication that might be ingested accidentally in a high dose by the elderly. More than $50 \%$ of the medications were purchased against the physician's prescriptions, whereas the remaining one-third were purchased either as nonprescription medications or due to the wrong practice of buying prescription medications without a prescription such as antibiotic medications. ${ }^{[15]}$ The appropriate method of disposal of medication is to return the unused medications to the pharmacy; this practice was followed by only $3 \%$ of the respondents in this study. Therefore, we propose that pharmacists should work on educating and increasing the awareness of the public regarding disposal of medications for example returning the used medications to the pharmacies in their area. Some respondents were also found to store more than one medication in the same container, more frequently for the medications that were repacked. This can lead to medication errors and poisoning.

The results of this study showed that more than twothirds of the responders stored their medications in original containers/packing and did not mix them with multiple drugs in the same container. This was true for the responders with high level of education, whereas responders with secondary level of education stored more drugs in one container. About 0.89\% medications were stored per patient which means that a considerable number of items were stored. The most frequently stored medications were paracetamol, which is used for relieve headache and other medications used to relieve pain and fever.

\section{ACKNOWLEDGEMENT}

None.

\section{CONFLICT OF INTEREST}

None.

\section{ABBREVIATIONS}

KSA: Kingdom of Saudi Arabia; SPSS: Statistical Packages for Social Sciences; WHO: World Health Organization. 


\section{REFERENCES}

1. World Health Organization. The pursuit of responsible use of medicines: sharing and learning from country experiences. World Health Organization; 2012.

2. Brahma D, Marak M. Rational Use of Drugs and Irrational Drug Combinations. Internet J Pharmacol. 2012;10(1).

3. Ofori-Asenso R, Agyeman A. Irrational Use of Medicines - A Summary of Key Concepts. Pharmacy. 2016;4(4):35.

4. Mekonnen T, Fentie M. Unused Medications Disposal Practice : The case of Patients Visiting University of Gondar Ethiopia. Int J Pharma Sci Res . 2014;5(12):999-1005.

5. Gitawati R. Pattern of Household Drug Storage. J Kesehat Masy Nas V. 2014;9(1):27-31.

6. Zaghloul AA, Elsergany M, El-Enein NA, Alsuwaidi H, Ayoub M. Overthe-counter medication patterns in households in Sharjah, United Arab Emirates. Risk Manag Healthc Policy. 2013;7:19-24.

7. Wasserfallen JB, Bourgeois R, Büla C, Yersin B, Buclin T. Composition and cost of drugs stored at home by elderly patients. Ann Pharmacother. 2003;37(5):731-7.

8. Vacas Rodilla E, Castell Dag I, Sánchez Giralt M, Pujol Algué A, Pallarés Comalada MC, Balagué Corbera M. Automedicación y ancianos. La realidad de un botiquín casero. Aten Primaria. 2009;41(5):1-6.
9. Ocan M, Bbosa GS, Waako P, Ogwal-Okeng J, Obua C. Factors predicting home storage of medicines in Northern Uganda. BMC Public Health. 2014;14(1):1-7.

10. Abou-Auda HS. An economic assessment of the extent of medication use and wastage among families in Saudi Arabia and Arabian Gulf countries. Clin Ther. 2003;25(4):1276-92.

11. Abahussain EA, Ball DE, Matowe WC. Practice and opinion towards disposal of unused medication in Kuwait. Med Princ Pract. 2006;15(5):352-7.

12. Wondimu A, Molla F, Demeke B, Eticha T, Assen A, Abrha S, et al. Household storage of medicines and associated factors in Tigray Region, Northern Ethiopia. PLoS One. 2015;10(8):1-9.

13. Kheir N, El Hajj MS, Wilbur K, Kaissi RML, Yousif A. An exploratory study on medications in Qatar homes. Drug Healthc Patient Saf. 2011;3(1):99-106.

14. Jassim A-M. In-home Drug Storage and Self-medication with Antimicrobial Drugs in Basrah, Iraq. Oman Med J. 2010 ;25(2):79-87.

15. McNulty CA, Boyle P, Nichols T, Clappison DP, Davey P. Antimicrobial Drugs in the Home, United Kingdom. Emerging Infectious Diseases. 2006;12(10):1523-6.

Cite this article as: Alenazi AB, Alsharidah MS, Al-Najjar AH, Alghazy SA, Alqadi AA, Marzouk A. Medication Storage at Home among People in Al-Qassim Region, Saudi Arabia. Int J Pharmacol. Clin. Sci. 2019;8(1):52-9. 